\title{
The benefits of computed tomography imaging in the diagnosis, prognosis and treatment planning of equine orthopedic patients illustrated by six cases
}

\author{
De voordelen van computertomografie in de diagnose, prognose en behandeling \\ van orthopedische aandoeningen bij het paard: zes casussen
}

\author{
${ }^{* 1}$ L. M. J. Vandekerckhove, ${ }^{* 1}$ E.V. Raes, ${ }^{2}$ M. Dumoulin, ${ }^{2}$ A. Martens, ${ }^{1}$ K. Vanderperren
}

${ }^{1}$ Department of Morphology, Imaging, Orthopedics, Rehabilitation and Nutrition,

Faculty of Veterinary Medicine, Ghent University, Salisburylaan 133, 9820 Merelbeke, Belgium

${ }^{2}$ Department of Large Animal Surgery, Anesthesia and Orthopedics, Faculty of Veterinary Medicine, Ghent University, Salisburylaan 133, 9820 Merelbeke, Belgium

*Both authors contributed equally

Louis.Vandekerckhove@UGent.be

\section{$\Lambda_{\text {bstract }}$}

Radiography and/or ultrasonography are the first imaging modalities for diagnosing orthopedic pathology in equine patients. However, in some cases, cross-sectional imaging is necessary to reach a more accurate diagnosis. Six cases were retrospectively selected from the imaging database of the Faculty of Veterinary Medicine (Ghent University) to illustrate the benefits of computed tomography (CT) in orthopedic patients. In two cases, CT demonstrated osteomyelitis lesions in two young foals, which could not be detected with radiography and ultrasonography. In three cases, CT was performed for surgical planning of fracture repair, and in one case CT demonstrated multiple lesions at the soft tissues and ligamentous insertions in the stifle. In all cases, CT revealed additional findings, which were important for the treatment and prognosis of the patient.

\section{SAMENVATTING}

Radiografie en/of echografie zijn de eerste beeldvormingsmodaliteiten die gebruikt worden voor de diagnose van orthopedische problemen bij paarden. In sommige gevallen is een accuratere diagnostiek noodzakelijk door middel van cross-sectionele beeldvorming. Zes klinische gevallen werden retrospectief geselecteerd uit de database van de dienst Medische Beeldvorming van de Faculteit Diergeneeskunde (Universiteit Gent) om de toegevoegde waarde van computertomografie (CT) aan te tonen bij orthopedische patiënten. Bij twee gevallen kon via CT osteomyelitis gedetecteerd worden bij jonge veulens, wat niet op radiografie of echografie werd vastgesteld. In drie gevallen waarbij de radiografische diagnose een fractuur was, werd CT uitgevoerd voor een betere chirurgische planning. In één geval werden meerdere wekedelenletsels ter hoogte van de knie aangetoond op CT. In alle gevallen bracht het CT-onderzoek bijkomende bevindingen aan het licht die de prognose en behandeling voor de patiënt veranderden.

\section{INTRODUCTION}

Computed tomography (CT) is a cross-sectional imaging technique which has numerous advantages over conventional radiography as it provides detailed anatomical information where multiple soft tissues and bony structures overlap. Computed tomography provides a higher degree of contrast resolution and enables the performance of 3D multiplanar reconstructed images in sagittal, transverse and dorsal planes. Therefore, CT is routinely used in the diagnostic work-up of equine patients and for surgical planning. 
Computed tomography of horses can be performed both under general anesthesia and on the standing horse depending on the examined region. CT of the equine head and the cranial cervical region is more and more performed on the standing horse where either a sliding gantry or a stationary gantry is used. Recently, a multi-slice helical unit is also available on the equine market for standing CT of the fetlock and the foot region and has demonstrated its feasibility (Mageed, 2020). With the increased availability of CT scanners in equine practice, the amount of CT examinations in the horse industry is increasing.

In this article, six clinical cases of horses with orthopedic problems are presented which underwent a CT examination to illustrate the advantages of CT over radiography and/or ultrasonography in the diagnosis and surgical planning and/or correct treatment.

\section{MATERIAL AND METHODS}

Radiographs were taken with a Philips Optimum generator (Philips N.V., Eindhoven, the Netherlands) and AGFA DR or CR plate (AGFA-Gevaert N.V., Mortsel, Belgium). Ultrasound examinations were performed with a Philips CX50 ultrasound system (Philips N.V, Eindhoven, the Netherlands).

All CT examinations were performed under general anesthesia using a 320-row scanner (Aquilion One, Canon Medical Systems, Tokyo, Japan). The following parameters were used for the CT image acquisition depending on the body part: slice thickness 0.5 $\mathrm{mm}$, rotation time $0.5 \mathrm{~s}$, exposure settings between $360-600 \mathrm{~mA}$ and $135 \mathrm{kV}, 512 \times 512$ matrix. For postcontrast images, iodinated contrast medium (Iomeron $300 \mathrm{mg} \mathrm{I} / \mathrm{ml}$; Bracco Imaging Deutschland $\mathrm{GmbH}$, Konstanz, Germany) was injected via both the left and right jugular veins with a power injector at a dose $2 \mathrm{ml} / \mathrm{kg}$ body weight or standard $400 \mathrm{~mL}$ if the patient exceeded $200 \mathrm{~kg}$ body weight.

\section{CASE DETAILS}

\section{Case 1}

A ten-day-old, male Haflinger foal was presented for recent left hind lameness. The foal was born a terme and without complications. Clinical examination demonstrated distension of the left tibiotarsal joint and severe left hind lameness at walk. Punction of the tibiotarsal joint revealed macroscopically normal appearing synovial fluid with normal white blood cell parameters. A snap foal test showed gamma globulins within the normal reference values. Blood work revealed marked elevation of SAA $(2091 \mu \mathrm{g} / \mathrm{ml})$ suspicious of an infectious etiology. Radiographic examination (lateromedial and dorsoplantar projections) demonstrated soft tissue swelling dorsal to the distal tarsal region and at the level of the tibiotarsal joint re- cesses. The lateral aspect of the third tarsal bone was irregularly marginated and this was considered more likely due to ongoing ossification of the tarsal bones, but crushing of the cartilaginous precursor of the third tarsal bone or osteomyelitis were also included as differential diagnoses (Figure 1). Native CT and postcontrast IV CT were performed for further investigation of the source of infection and lameness: the foal was scanned from the caudal thoracal region until and including the distal limbs. For practical reasons, both hind limbs were included in the scan. CT images confirmed the distension of the tibiotarsal joint and the pronounced soft tissue swelling at the dorsal aspect of the distal tarsus. Additionally, the CT images showed multiple ill-marginated moth-eaten hypoattenuating osteolytic areas of the cortex and medulla at the dorsolateral aspect of the third tarsal bone. This region was bordered by a severe amount of increased mineral attenuation (sclerosis) in the dorsolateral and to a lesser extent in the dorsomedial aspects. The height of the third tarsal bone decreased mildly towards lateral and dorsal giving it a wedge-shaped appearance. The proximal and distal subchondral bone plates were interrupted at multiple sites. Approximately one third of the third tarsal bone was affected (Figure 2). No other abnormalities were detected and a type $\mathrm{T}$ osteomyelitis of the third tarsal bone with signs of crushing of the bone and infectious arthritis of the distal intertarsal and tarsometatarsal joints were concluded. The tibiotarsal joint effusion was considered secondary inflammatory to the adjacent infectious process. The tarsometatarsal joint was punctured and the obtained synovial fluid contained $23000 \mathrm{WBC} / \mathrm{mm} 3$. Actinobacillus equili and Staphylococcus equorum were isolated from the fluid and antibiotic treatment was changed according to the resulting antibiogram. Control radiographs of the left tarsus were repeated nine days and three weeks after initial presentation. The first control radiographs showed diminished soft tissue swelling and at this time clear lytic lesions at

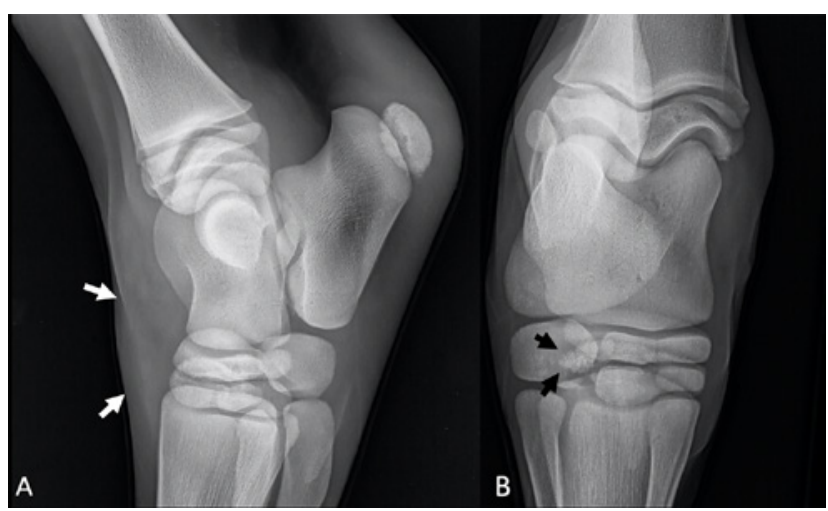

Figure 1. Case 1: A. Lateromedial and B. dorsoplantar projections of the left tarsus of the foal at initial presentation. Note the soft tissue swelling dorsal to the distal aspect of the tarsus (white arrows). The lateral aspect of the third tarsal bone is irregularly marginated (black arrow). 


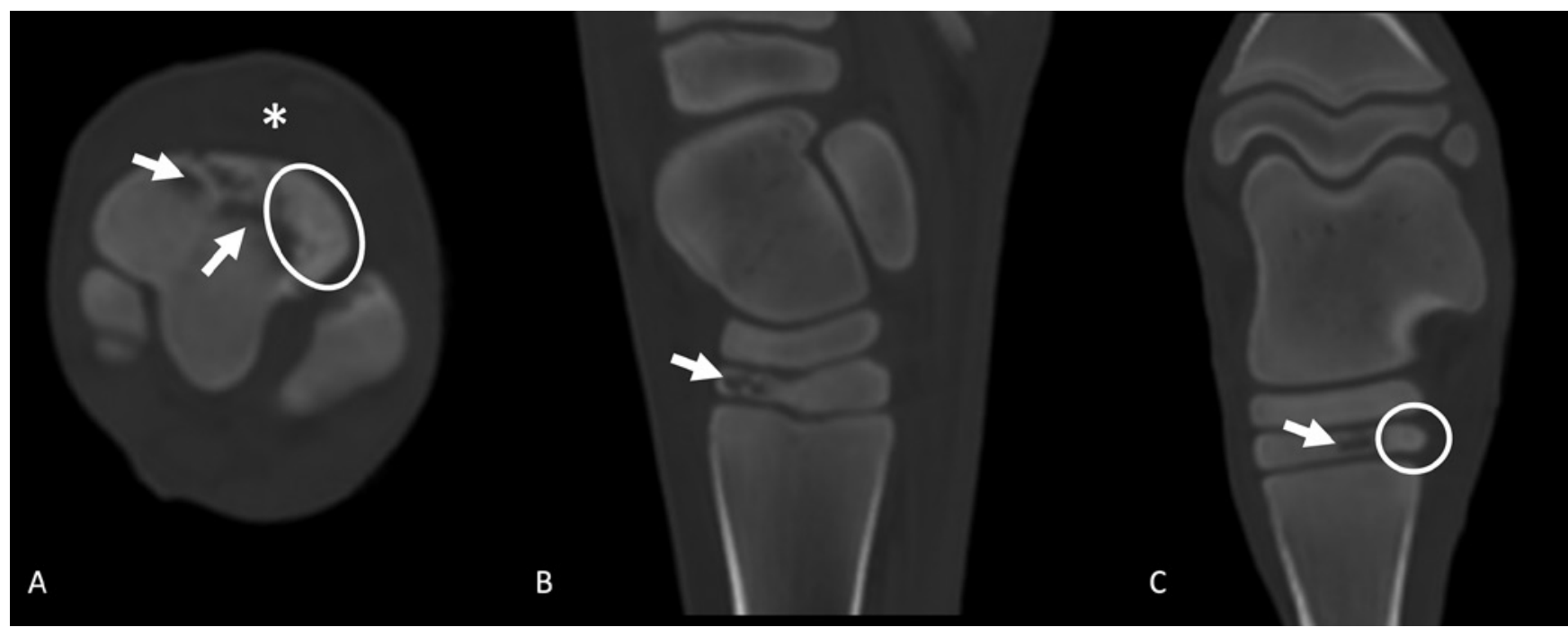

Figure 2. Case 1: A. Transverse, B. sagittal and C. dorsal reconstructed CT images of the left tarsus. Medial is to the left. The arrows indicate the irregular shaped, ill-defined lytic areas in the dorsolateral aspect of the third tarsal bone bordered by a region of increased mineral attenuation (sclerosis) in the dorsolateral aspect (encircled). The asterisk indicates the soft tissue swelling dorsal to the distal tarsal region.

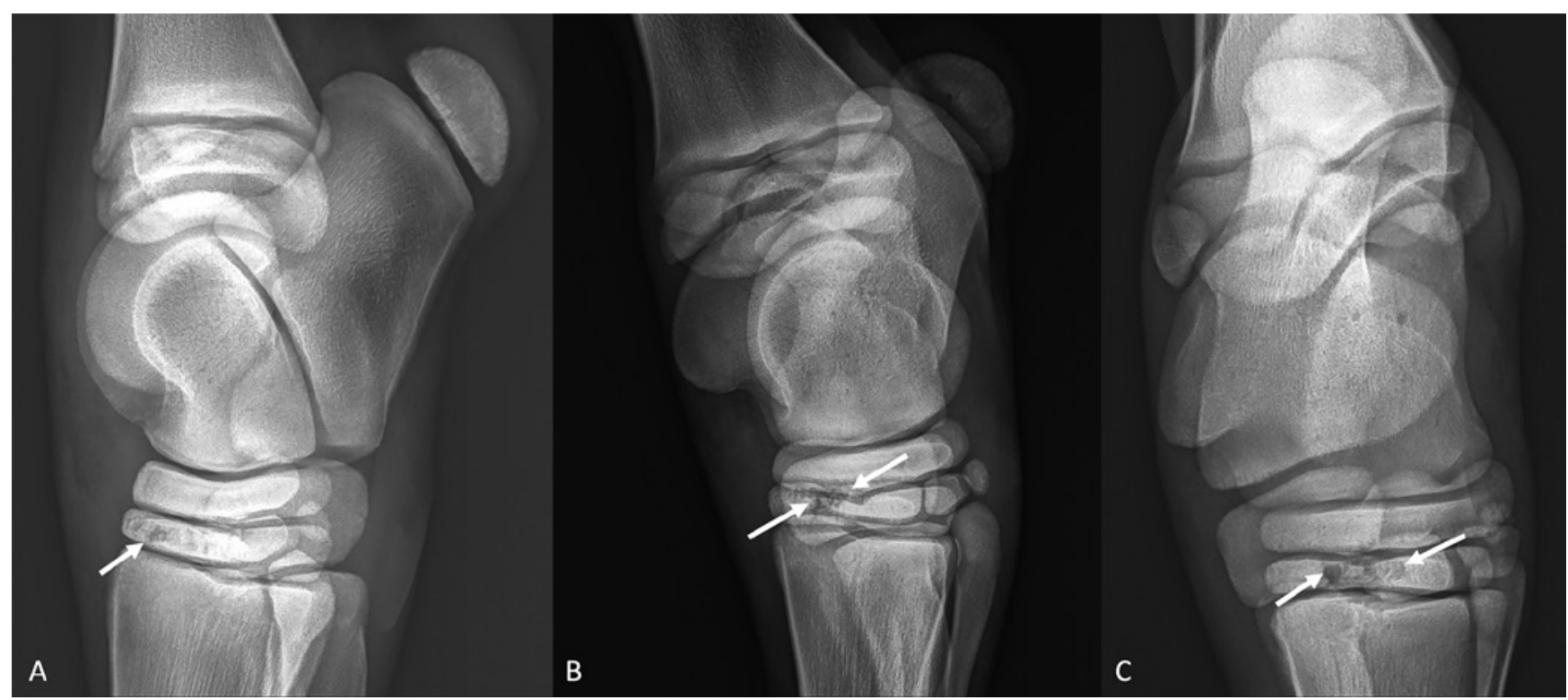

Figure 3. Case 1: A. Lateromedial, B. dorsomedial-plantarolateral oblique and C. dorsoplantar projections of the left tarsus after nine days. The white arrows indicate the lucent areas in the third tarsal bone. Note the third tarsal bone is slightly wedge shaped.

the dorsal half of the third tarsal bone surrounded by increased mineral opacity (sclerosis) were detected. The third tarsal bone was slightly wedge-shaped and there was a moderate amount of ill-defined palisading new bone formation at the dorsoproximal aspect of the third metatarsal bone. The proximal subchondral bone plate of the third metatarsal bone was mildly irregularly outlined (Figure 3 ). In the second control examination, there was similar mild persistent soft tissue swelling dorsal to the distal tarsal region. The lytic areas in the dorsal half of the third tarsal bone had decreased in size, were better defined, and surrounded by sclerosis (Figure 4). The serum SAA decreased to normal reference values, bacteriologic examination using blood culture medium (Bactec, Becton Dickinson and
Company, Franklin Lakes, New Jersey, United States of America) of the synovial fluid was negative and the foal was discharged from the clinic. Systemic antibiotics and box rest were advised. Six weeks later, the foal was clinically and radiographically re-evaluated. The foal was not lame at walk and at the trot on a straight line. Radiographs demonstrated further reduced soft tissue swelling, there was only mild focal swelling centered at the dorsal aspect of the small tarsal bones. The lytic areas in the third tarsal bone were not detected anymore, the dorsal aspect was still mildly heterogeneous with a better demarcation between the cortical and medullary bone. The dorsal aspect of the distal intertarsal and tarsometatarsal joints spaces were mildly irregular and there was periarticular new 


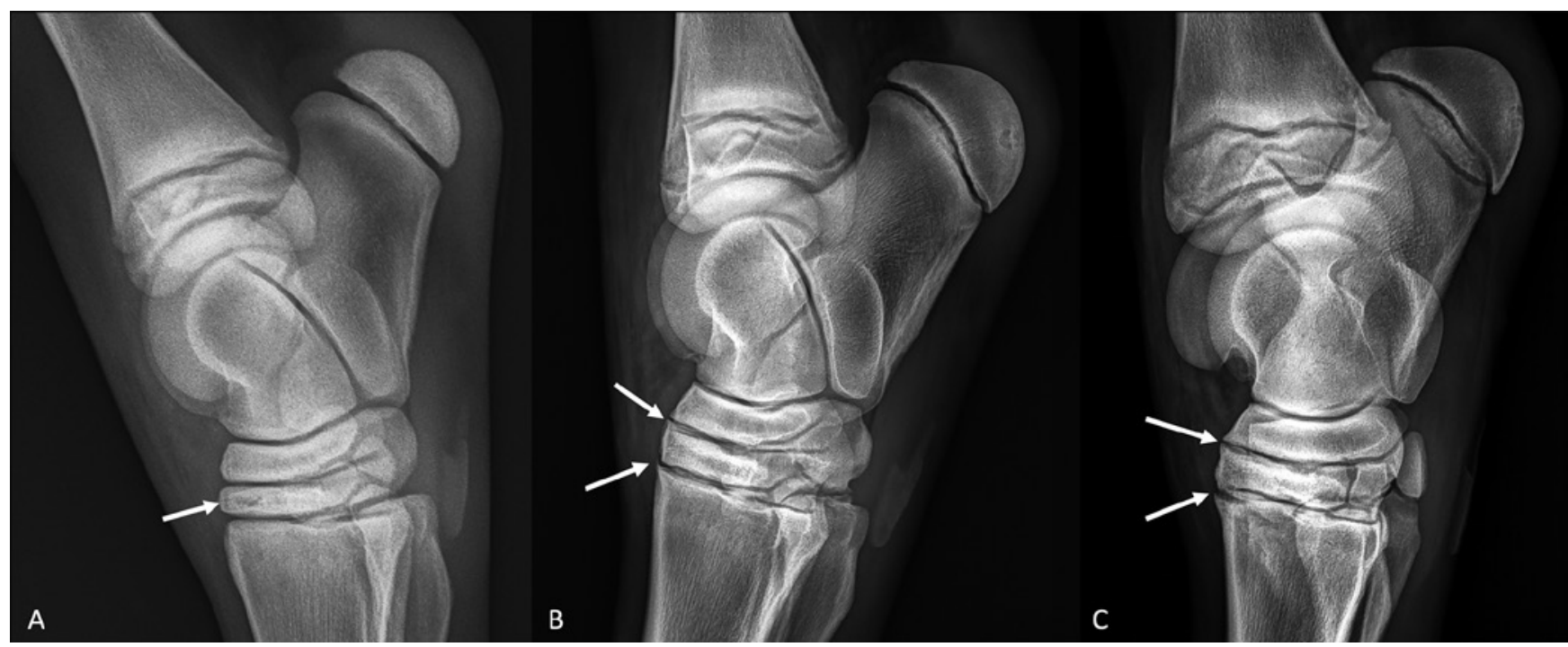

Figure 4. Case 1: A. Lateromedial view three weeks after initial presentation and B. lateromedial and C. dorsomedialplantarolateral projections two months after initial presentation. A. The arrow indicates the small lucent area remaining at the dorsal aspect of the third tarsal bone. $B$. and $C$. The arrows indicate the periarticular new bone formation at the dorsal and more pronounced at the dorsolateral aspects of the distal intertarsal and tarsometatarsal joints. Note the distal intertarsal and tarsometatarsal joint spaces are mildly irregularly outlined in the dorsal aspect and the third tarsal bone demonstrates better demarcation between the medulla and cortex.

bone formation at the dorsal aspect of the involved joints. The previously mentioned wedge shape of the third tarsal bone was not evident anymore. Resolution of the type T osteomyelitis of the third tarsal bone with degenerative changes of the distal intertarsal and tarsometatarsal joints was concluded.

\section{Case 2}

A twenty-day-old warmblood foal was presented for recent onset of left hind lameness. On clinical examination, the foal demonstrated severe lameness at walk and both hind limbs were diffusely swollen. There were no joint effusions noted. A pelvic problem was suspected, and radiography (ventrodorsal and laterolateral projections) and ultrasonography of the pelvis were performed. Both examinations were unremarkable. Radiographs of the left hind fetlock and left stifle were within normal limits. Serum SAA was markedly elevated $(2808 \mu \mathrm{g} / \mathrm{ml})$ suggesting an infectious etiology. A CT examination (including a postcontrast scan after IV injection of iodinated contrast

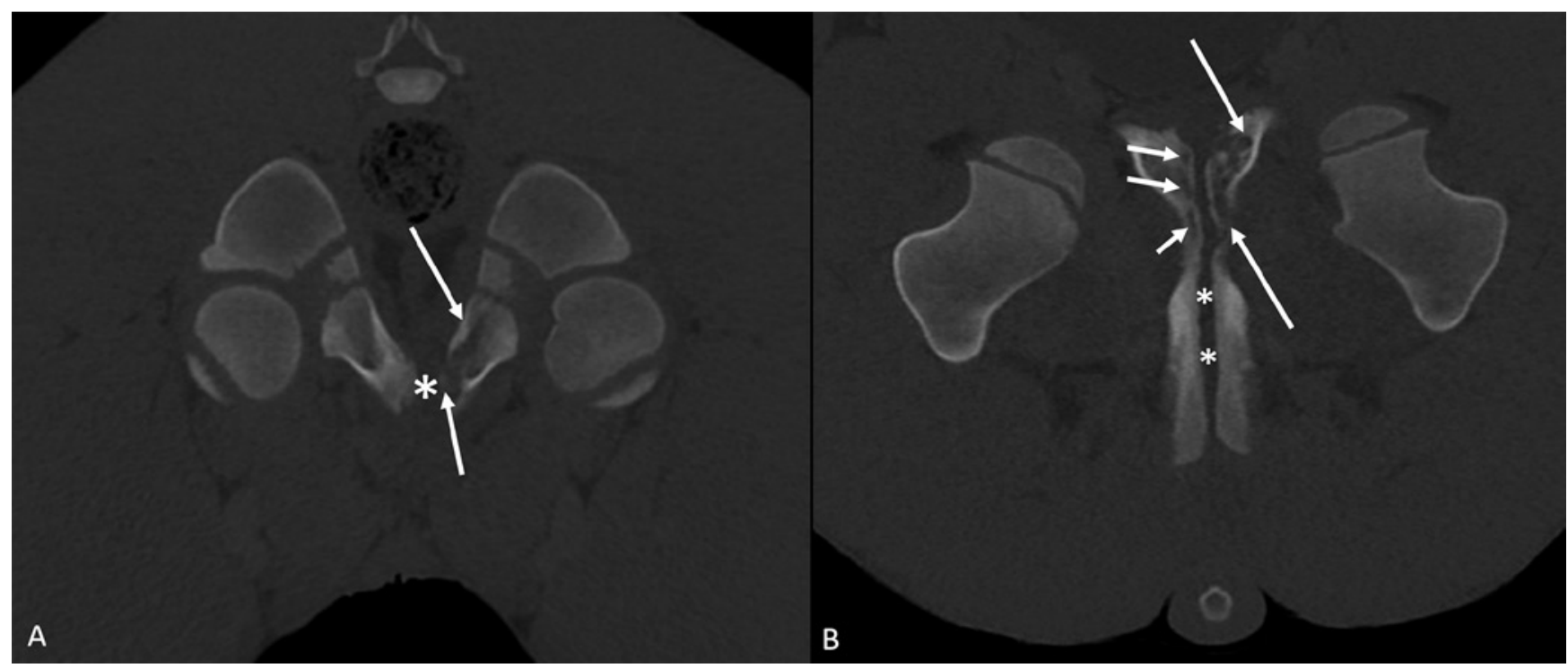

Figure 5. Case 2: A. Transverse and B. dorsal reconstructed CT images of the pelvis at the level of the pubic bones presented with bone filters. In both images, left is right side of the patient. In the left image, top is dorsal of the patient and in the right image top is cranial of the patient. The long white arrows indicate the ill-defined lytic regions in the left pubic bone, the short arrows indicate some smaller lytic areas in the right pubic bone. The white asterisks indicate the cartilaginous symphysis between both pubic bones. 
medium) was performed of the lumbar spine, pelvis and both hind limbs. CT images revealed marked patchy hypoattenuation (osteolysis) of the cortical and trabecular bone of the left and to a lesser extent of the right pubic bones. The right pubic bone was also moderately affected. The cortical bone was disrupted. There was a small amount of poorly mineralized periosteal new bone formation at the ventrolateral aspect of the left pubic bone and a smaller amount of welldefined periosteal new bone at the cranioventrolateral aspect of the right pubic bone (Figure 5). A moderate amount of heterogeneous soft tissue attenuating material was surrounding the pubic bones with a moderately sized hypoattenuating region at the dorsolateral aspect of the left pubic bone surrounded by a rim of faint contrast enhancement $(2.7 \times 1.7 \times 2.8 \mathrm{~cm})$ (Figure 6). The left medial iliac lymph node was moderately increased in size $(2.9 \times 1.1 \times 3.1 \mathrm{~cm})$. The final diagnosis was osteomyelitis of both pubic bones with intrapelvic abscess formation. Unfortunately, this region was not safely accessible for sampling and the foal was treated with a combination of rifampicine and clarythromycine. Because serum SAA remained high, antibiotic treatment was changed to oxytetracycline. When the serum SAA level returned to normal values, the foal was treated with oral doxycycline. No follow-up was available for this patient.

\section{Case 3}

A fifteen-month-old warmblood stallion was found fracture lame at the right front limb after falling on the

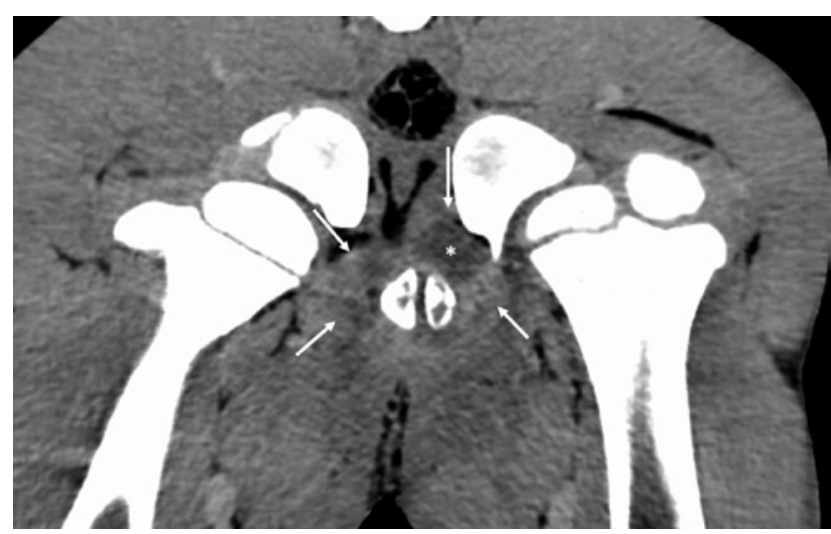

Figure 6. Case 2: Transverse CT image at the level of the coxofemoral joints presented with soft tissue filters after IV injection of iodinated contrast medium. Left is the right side of the patient. The white arrows indicate the heterogeneous soft tissue attenuation swelling surrounding the pubic bones and the white asterisk indicates a rounded fluid attenuating cavity surrounded by rim enhancement indicative of an abscess.

pasture. Radiographs from the referring veterinarian revealed a displaced fracture of the tuberculum supraglenoidale.

During clinical examination, the horse was in good general condition, but was severely lame, with mild lateral deviation of the shoulder region during walk.

Radiography (mediolateral and cranioproximalcraniodistal oblique projections) of the right shoulder revealed a moderate degree of soft tissue swelling cranial to the shoulder joint, most obvious on the cranioproximal-craniodistal oblique view. A wide, well-

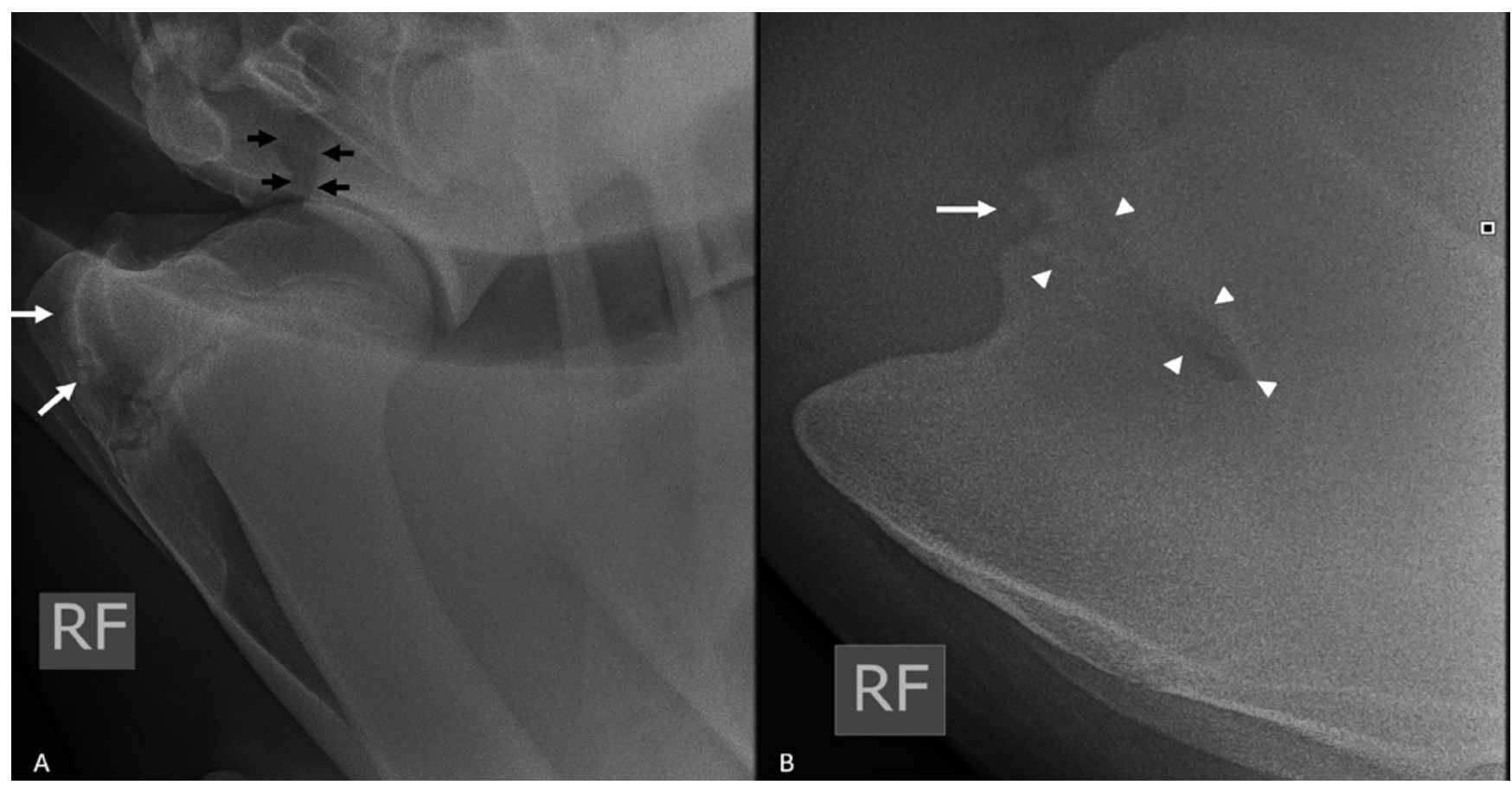

Figure 7. Case 3: A. Mediolateral and B. cranioproximal-craniodistal oblique projections (lateral is to the left) of the right shoulder, showing an ill-defined wide radiolucent line (black arrows) separating the supraglenoid tubercle from the body of the scapula with distal and cranial displacement. The intermediate tubercle of the humerus is irregularly outlined (white arrows). Two adjacent ill-defined fragments are noted. The white arrowheads indicate an ill-defined wide radiolucent zone going from the level of the intermediate tubercle of the humerus in a craniocaudal direction. 
defined, irregular radiolucent line was separating the supraglenoid tubercle from the body of the scapula (6.9 $\mathrm{mm}$ to $15 \mathrm{~mm}$ gap) resulting in a distal and cranial displacement. The cranial contour of the intermediate tubercle of the humerus was moderately irregularly marginated. Two well-defined, rounded ( 2.5 $\mathrm{mm}$ in diameter) to ovoid $(3.3 \mathrm{~mm} \times 5.1 \mathrm{~mm})$ and homogeneous bone fragments were located along the craniodistal border of the intermediate tubercle (Figure 7A), and an ill-defined, radiolucent line going in a craniocaudal plane was noted between the intermediate and greater tubercles of the humerus (Figure 7B).

For further assessment of the fracture configuration and associated soft tissue trauma, ultrasonography was performed. Ultrasonography confirmed a markedly displaced fracture of the tuberculum supraglenoidale, surrounded by heterogeneous soft tissue swelling representing hematoma formation. The proximal part of the biceps tendon was markedly enlarged, especially its lateral lobe, and its fibers demonstrated an undulating appearance on longitudinal scan. There was a marked anechoic distention of the bursa bicipitalis, with echoic material (synovial proliferations). The osseous surface at the level of the intermediate tubercle of the humerus was markedly irregularly outlined with at least two hyperechoic foci with distal acoustic shadowing and deep penetration of the echoes through the osseous surface of the lateral intertubercular sulcus of the humerus (Figure 8).

CT was performed for surgical planning and further examination of the lateral intertubercular sulcus of the humerus. CT demonstrated an irregular, welldefined fracture line at the right supraglenoid tubercle with craniodistal displacement and craniomedial rotation. The fragment to which the biceps brachii tendon was still attached could be exactly measured $(2.4 \mathrm{~cm}$ x $6 \mathrm{~cm} \times 5 \mathrm{~cm}$ ), thus allowing a correct planning of the implants to be used for surgical fixation. Three ad-

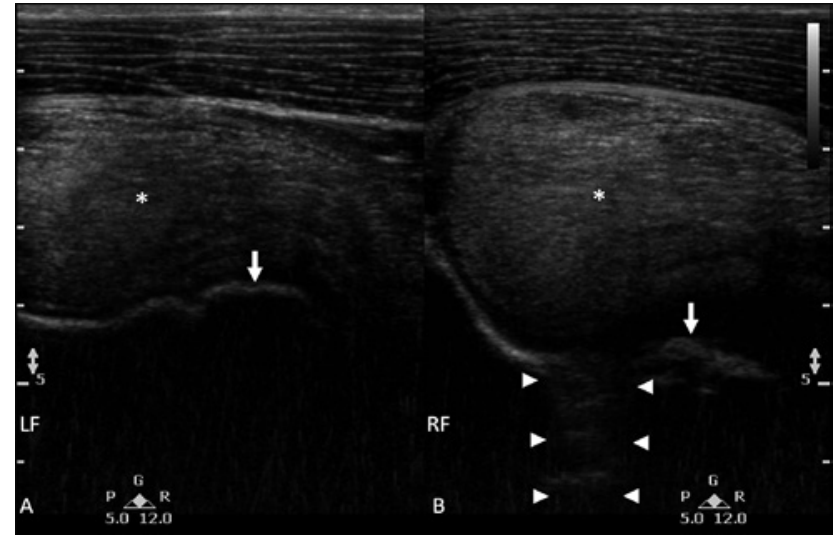

Figure 8. Case 3: Transverse ultrasound images of the A. left and B. right proximal humerus. Lateral is to the left on both images. The asterisk indicates the biceps tendon, which is markedly thickened on the right compared to the left. The osseous surface is interrupted and echoes are penetrating the bone (white arrowheads) between the intermediate tubercle (white arrow) and the greater tubercle of the humerus.

ditional smaller fragments, which were not detected on radiography, could be identified: one $(8 \mathrm{~mm} \times 2.5$ $\mathrm{mm} \times 8 \mathrm{~mm}$ ), well-defined bone fragment located at the caudodistomedial aspect of the displaced supraglenoid tubercle and two small bone fragments were still attached at the cranial aspect of the glenoid cavity, one lateral (triangular shaped measuring $9 \mathrm{~mm} \times 8 \mathrm{~mm} x$ $14 \mathrm{~mm}$ ) and one medial (triangular shaped measuring $16 \mathrm{~mm} \times 5 \mathrm{~mm} \times 20 \mathrm{~mm}$ ) involving the articular surface of the glenoid cavity (Figures 9A and 9B).

On the CT images, it was evident that approximately $25 \%$ of the articular surface of the glenoid cavity was involved in the fracture, which was underestimated on radiography. The CT images confirmed the irregular outline of the intermediate humeral tubercle,

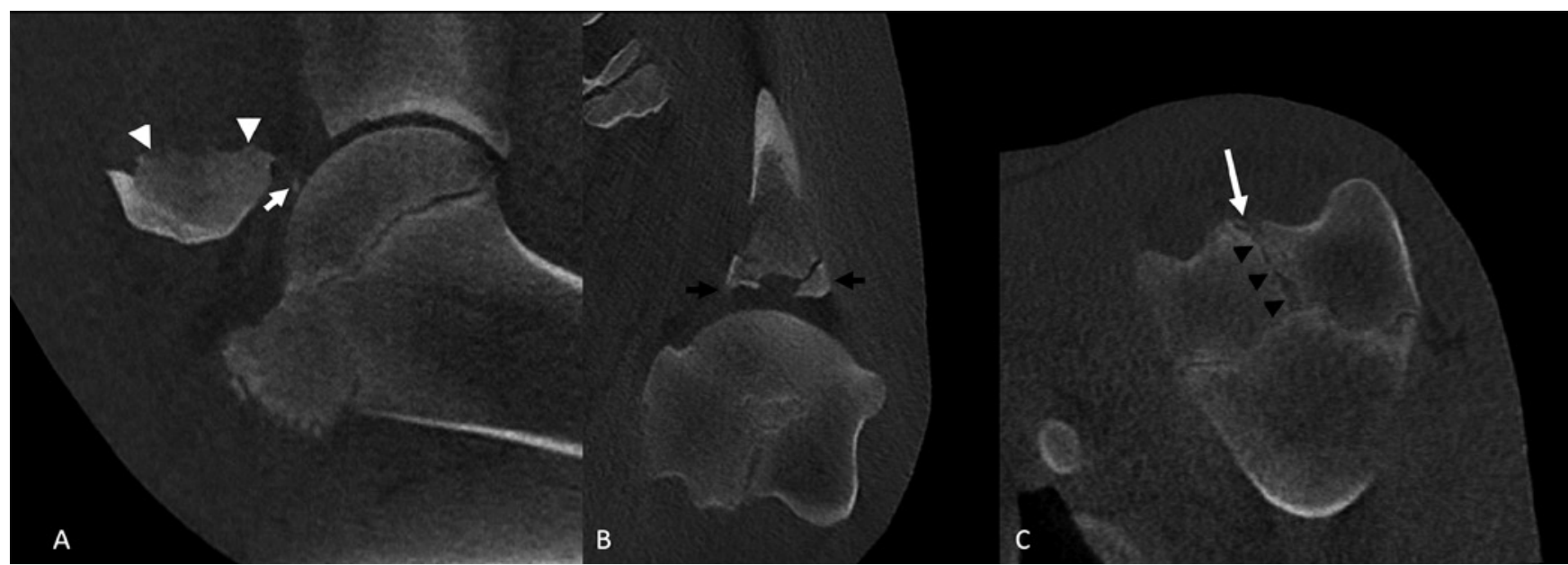

Figure 9. Case 3: Multiplanar CT reconstructions in A. sagittal, B. dorsal and C. transverse planes. Medial is to the left. The large fracture fragment of the supraglenoid tubercle is indicated by the white arrowheads. Additional fragments are noted in the fracture gap (white arrow) and lateral and medial to the cranial aspect of the glenoid cavity (black arrows). The Salter-Harris type III fracture is indicated by the black arrowheads just lateral to the intermediate tubercle of the humerus (large white arrow). 
and small bone fragments $(3 \mathrm{~mm})$ located adjacent to its osseous surface. An undulating hypodense line was interrupting the bone surface of the intermediate humeral tubercle running in a caudolateral direction and connecting to the physis between the humeral tubercles and the diaphysis of the humerus. This was indicative of a Salter-Harris type III fracture (Figure 9C).

Based on the CT findings, the horse underwent osteosynthesis of the supraglenoid tubercle with two LCP plates and a tension-band wire. The three small fracture fragments were localized based on the CT images and were removed. It was decided to manage the non-displaced Salter Harris type III fracture conservatively. Post-operative radiographs revealed good fracture apposition and no implant failure (Figure 10).

\section{Case 4}

A yearling was presented with a severe nonweightbearing left front limb lameness and a marked swelling at the level of the elbow region. Radiographic examination (mediolateral and craniocaudal projections) identified an oblique sharp radiolucent line interrupting the distal aspect of the ulna, approximately $10 \mathrm{~cm}$ distal to the ulnar notch. A second fracture line was present at the caudal aspect of the proximal epiphysis of the radius, starting at the proximal articular surface, running distally through the physis and caudal aspect of the metaphysis, interrupting the caudal cortex of the metaphysis resulting in a thin caudal fragment. There was a cranial and lateral displacement of the radius in relation to the proximal ulna and humerus. Additional fragmentation was present in the fracture gap (Figure 11). The radiographic diagnosis was an acute, displaced, closed articular, Salter Harris type IV of the radius with luxation of the elbow joint (Monteggia type fracture of the elbow). CT examination was performed for the exact configuration and the exact localization of the fracture planes and fragments for surgical planning. CT images revealed the two fracture lines previously identified on the radiographs, one transverse hypoattenuating fracture line through the ulnar diaphysis and a second fracture line in the radius with a proximodistal orientation, involving the caudal aspect of the epiphysis and metaphysis. This resulted in a caudal thin fragment $(7 \mathrm{~cm} \mathrm{x} 1 \mathrm{~cm})$ with involvement of the caudal radial epiphysis and part of the metaphysis attached to the proximal ulna. There was a complete cranial displacement with an additional mild exorotation of the radius compared to the humeral condyles causing a large fracture gap with the presence of multiple thin and small bony fragments of different size and shape with one thin larger fragment $(3 \mathrm{~cm} \times 7 \mathrm{~mm})$ located medially and multiple fragments laterally.

The distal half of the lateral collateral ligament was only partially attached on the radius, and partially on a thin linear fragment $(1.5 \mathrm{~cm}$ x $5 \mathrm{~mm})$ with cor-

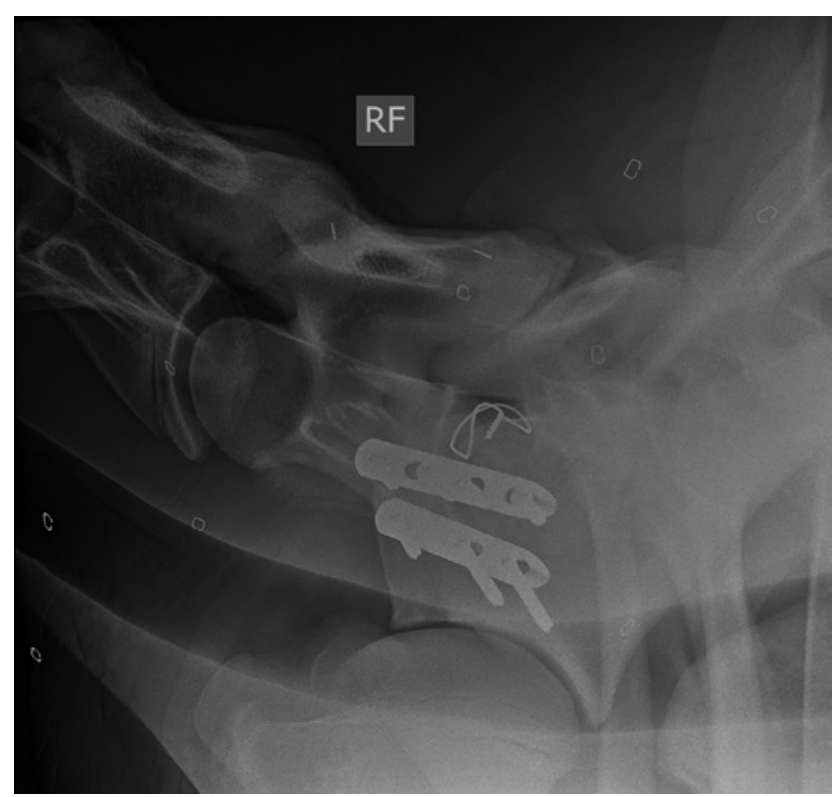

Figure 10. Case 3: a mediolateral post-operative radiograph revealed good fracture apposition with two LCP plates and a tension-band wire.

responding defect on the caudolateral aspect of the radial epiphysis, present in the lateral aspect of the fracture gap (Figure 12).

Based on the radiography and the CT findings, the horse underwent surgical repair by internal fixation under general anesthesia. First, multiple small fragments and one long fragment $(3 \mathrm{~cm} \times 0.5 \mathrm{~cm})$, which was part of the radial articular surface, were removed. After exposure of the fracture fragments and flushing of the fracture gap and joint, a reduction of the fracture was performed. The medial coronoid process of the ulna was fixed to the epiphysis of the radius using a $4.5 \mathrm{~mm}$ compression screw. Then a twelvehole-locking plate was placed at the caudal aspect of the ulna to fix the ulna to the radius using one cortical and eleven locking screws. Finally, an additional compression screw was placed between the lateral coronoid process of the ulna and the radial epiphysis. Post-operative radiographs revealed good fracture apposition and no implant failure (Figure 13).

\section{Case 5}

A two-year-old horse was presented with a wound and left hind lameness after the horse escaped when brought in from the pasture. Clinical examination revealed a deep wound (approximately $5 \mathrm{~cm}$ in length) at the dorsolateral aspect of the left metatarsophalangeal joint. Radiographic examination of the left metatarsophalangeal joint (lateromedial, dorsoproximal-plantarodistal, dorsolateral-plantaromedial oblique and dorsomedial-plantarolateral oblique projections) revealed a severe amount of soft tissue swelling surrounding the fetlock region, most pronounced at the dorsolateral aspect and centered on the recesses of the metatarsophalangeal joint. The soft tissues were fo- 


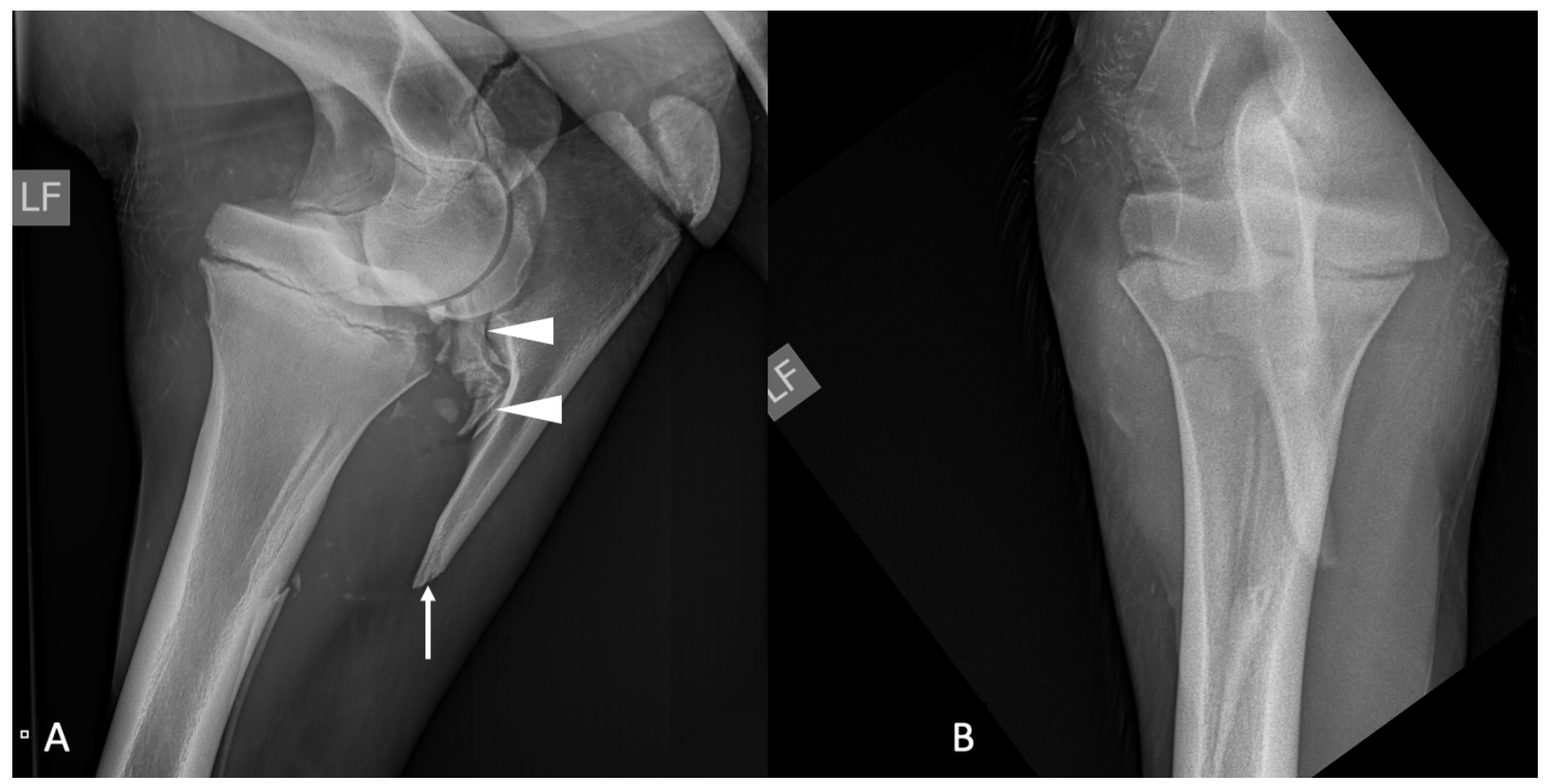

Figure 11. Case 4: A. mediolateral and B. craniocaudal projections with an oblique sharp radiolucent line interrupting the distal aspect of the ulna (arrow). A second fracture line is present at the caudal aspect of the proximal epiphysis of the radius, starting at the proximal articular surface, running distally through the physis and caudal aspect of the metaphysis, interrupting the caudal cortex of the metaphysis resulting in a thin caudal fragment (arrowheads). Note the cranial and lateral displacement of the radius in relation to the proximal ulna and humerus (Monteggia fracture). Additional fragmentation is present in the fracture gap.

cally irregularly outlined at the dorsal aspect of the fetlock region with multiple gas opacities superimposed on the soft tissues.

A well-defined, oblique, mildly curved fracture line was present at the lateral aspect of the lateral condyle of the third metatarsal bone. This fracture line interrupted the lateral aspect of the subchondral bone plate of the lateral condyle and was running in a proximomedial direction (proximodistal distance of $17 \mathrm{~mm}$ ). There was a mild displacement of the fragment in a dorsolateral direction and lateral collateral fossa of the third metatarsal bone was mildly hetero-

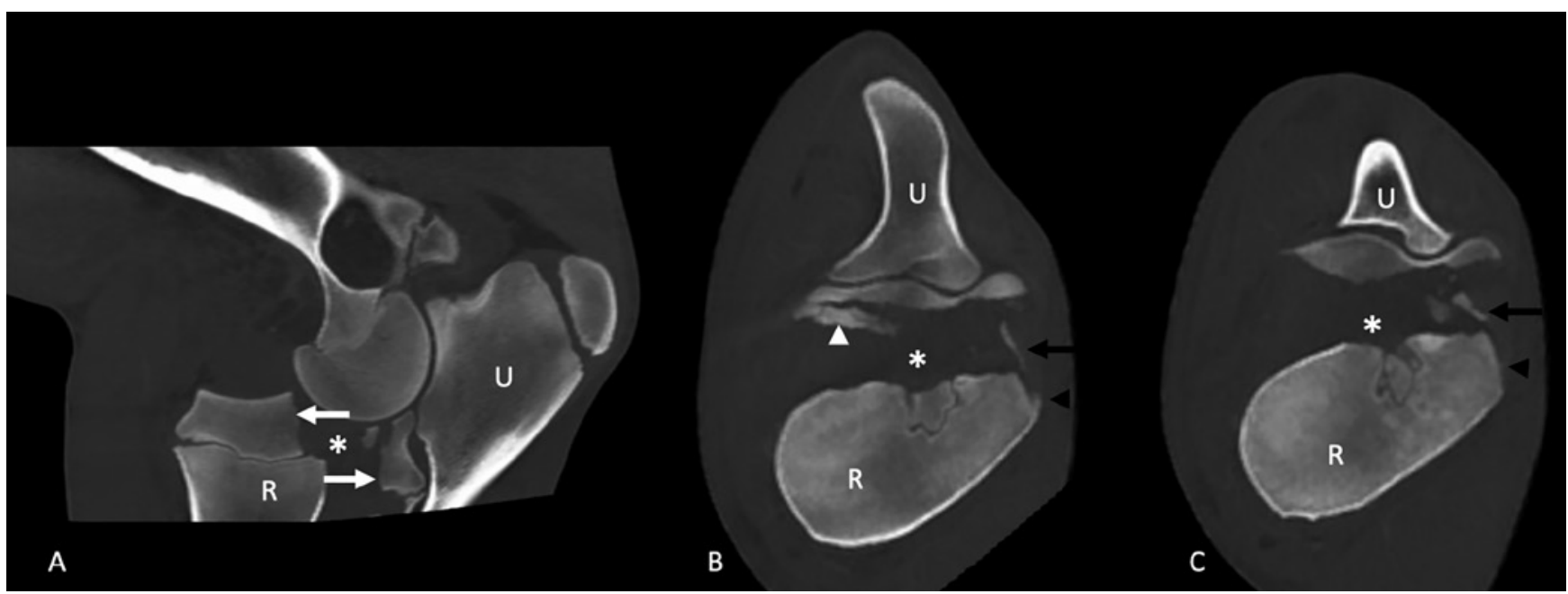

Figure 12. Case 4: Multiplanar CT reconstructions in A. sagittal and B. and C. transverse planes. Medial is to the left. The fracture line in the radius involving the caudal aspect of the epiphysis and metaphysis is indicated by the arrows. A large fracture gap is present (asterisk) with one thin larger fragment medially (white arrowhead) and multiple fragments in the fracture gap. A thin linear fragment (black arrow) is present in the lateral aspect of the fracture gap with corresponding defect on the caudolateral aspect of the radial epiphysis (black arrowhead) where a part of the lateral collateral ligament has been attached to. Note the complete cranial displacement with an additional mild exorotation of the radius $(\mathrm{U}=\mathrm{ulna}$; $\mathrm{R}=$ radius $)$. 


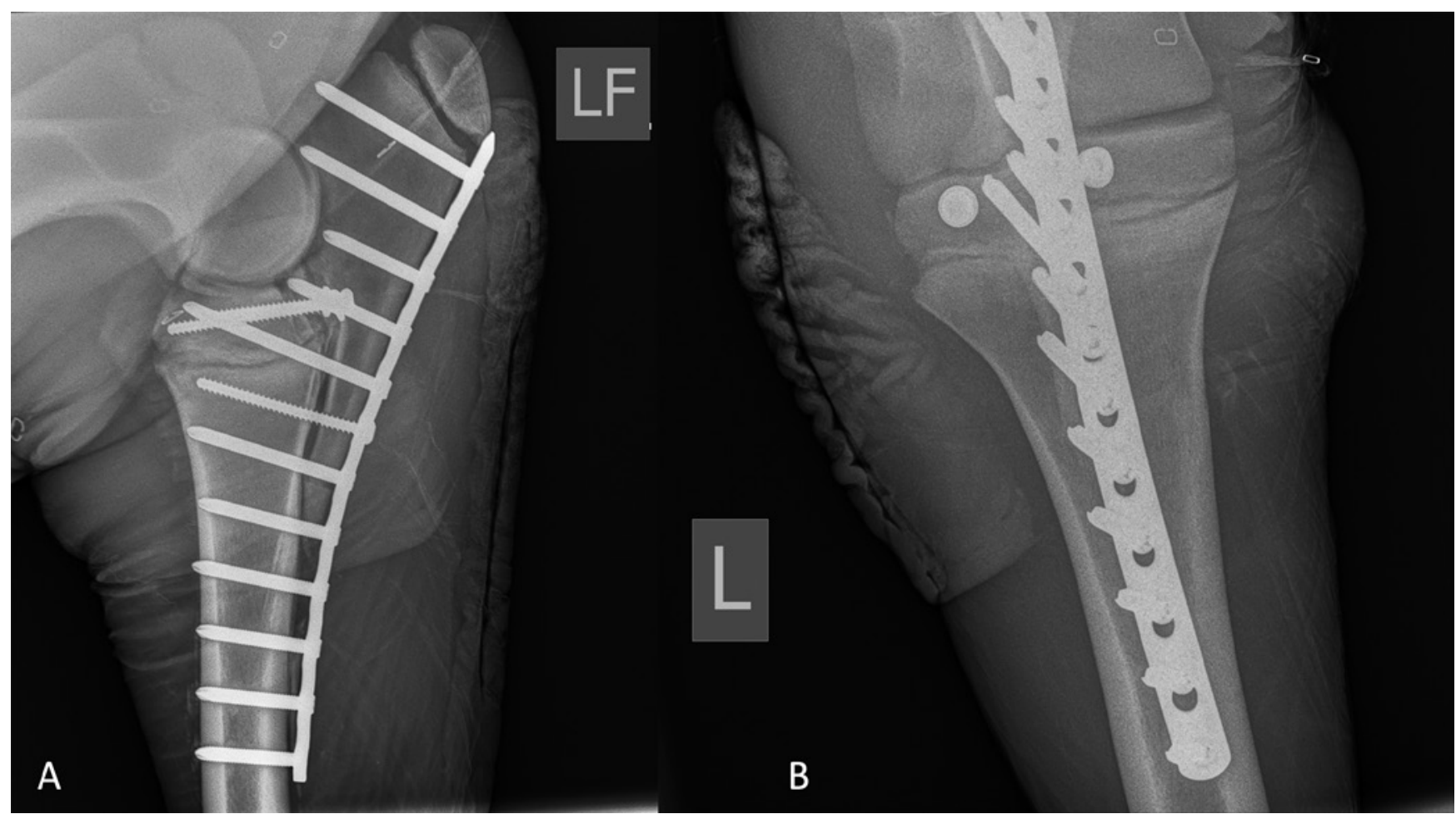

Figure 13. Case 4: A. Mediolateral and B. craniocaudal post-operative radiographs revealed good fracture apposition with two compression screws placed through the radius and a twelve-hole-locking plate fixed with one cortical and eleven locking screws at the caudal aspect of the ulna and radius.

geneous. A metal probe was inserted dorsally at the level of the soft tissue defect and the point of the probe ended at the dorsal margin of the condyles of the third metatarsal bone. The radiographic conclusion was an intrasynovial wound at the dorsal aspect fetlock joint with an acute, intra-articular fracture of the lateral condyle of the third metatarsal bone involving the lateral collateral fossa (Figure 14). CT was performed to determine the surgical planning by either fragment removal or fracture fixation.

The joint recesses of the metatarsophalangeal joint were severely distended with fluid attenuating mate-

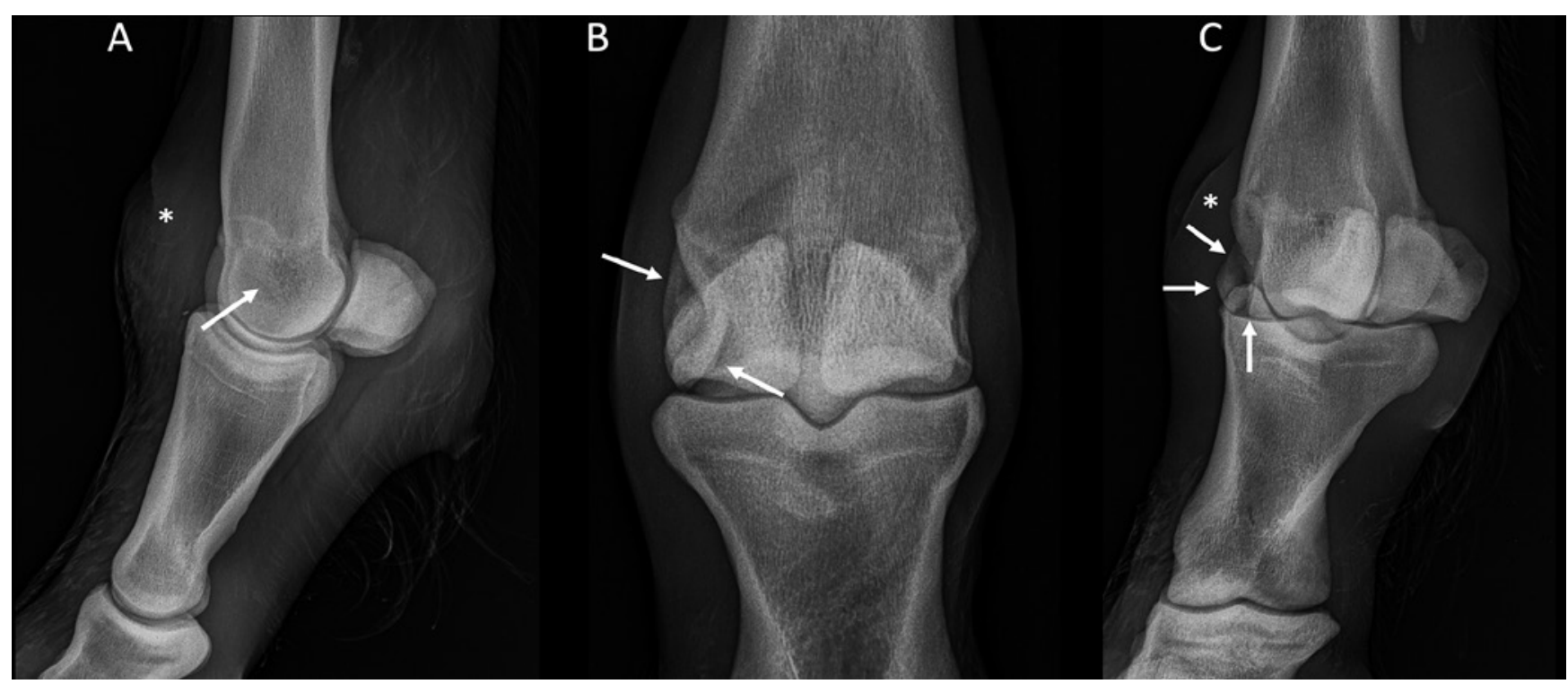

Figure 14. Case 5: A. Lateromedial, B. dorsoplantar, C. dorsomedial-plantarolateral oblique projections of the left metatarsophalangeal joint with a severe amount of soft tissue swelling surrounding the fetlock region and a wound at the dorsal aspect (asterisk). A. On the lateromedial projection, a curved radiolucent line is present (arrow). B. and C. A well-defined, oblique, mildly curved fracture line is present at the lateral aspect of the lateral condyle of the third metatarsal bone (arrows) interrupting the lateral aspect of the subchondral bone plate of the lateral condyle. There is mild displacement of the fragment in a dorsolateral direction. 


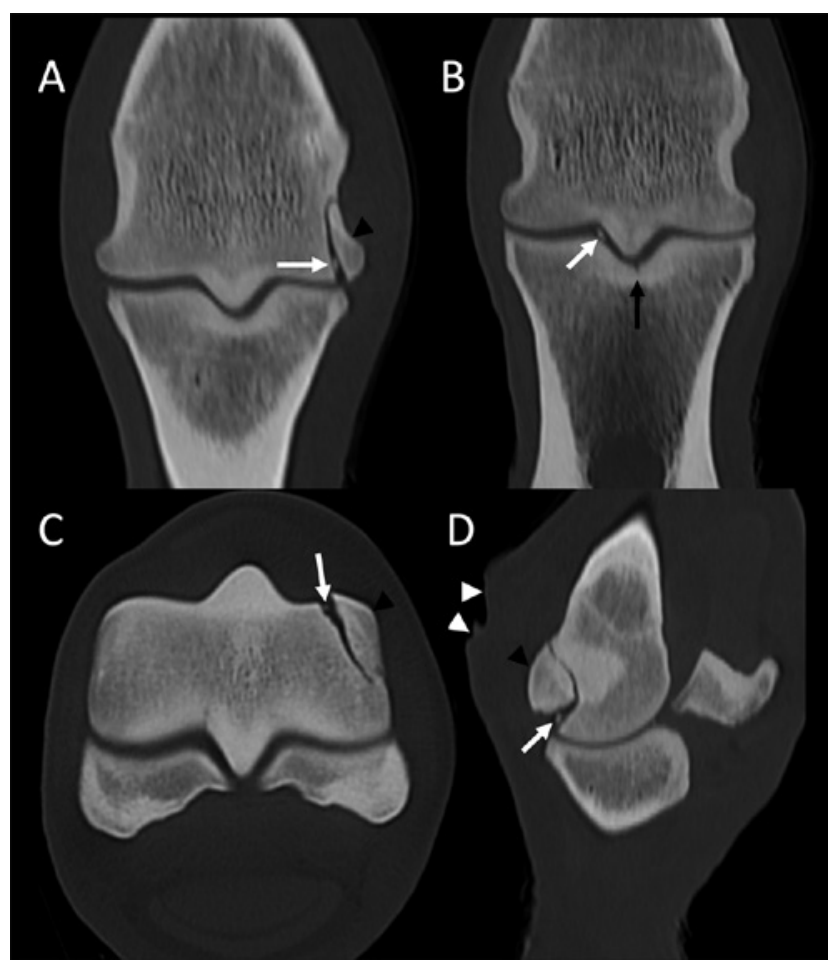

Figure 15. Case 5: Multiplanar CT reconstructions in A. and B. dorsal, C. transverse and D. sagittal planes demonstrating a well-defined fracture line with a proximodistal orientation, interrupting the subchondral bone of the lateral condyle of the third metatarsal bone and running to the lateral collateral fossa, resulting in a triangular fragment (black arrowhead), which is mildly angled and displaced distally and dorsally. Focal mineral debris is present at the fracture site and medial to the sagittal ridge of the third metatarsal bone (white arrow). A small short radiolucent line is present at the sagittal groove of the proximal phalanx (black arrow). Note the soft tissue interruption, corresponding to the wound (white arrowhead). Medial is to the left.

rial combined with soft tissue attenuating proliferations, which were most pronounced in the plantar recess. The lateral collateral ligament was moderately thickened, ill-defined and heterogeneous. There was a well-defined fracture line with a proximodistal orientation, interrupting the subchondral bone of the lateral condyle of the third metatarsal bone and running to the lateral collateral fossa, resulting in a triangular fragment, which was mildly angled and displaced distally and dorsally. The fracture fragment measured $14 \mathrm{~mm}$ in a proximodistal direction, $11 \mathrm{~mm}$ in a dorsoplantar direction and $6 \mathrm{~mm}$ in a laterolateral direction and occupied approximately $5 \%$ of the articular surface of the lateral condyle. Focal mineral debris was present at the fracture site. Three additional mineralized pinpoint mineral foci were detected in the plantar recess of the metatarsophalangeal joint. An additional small, thin linear fragment (length: $4 \mathrm{~mm}$; width: $1 \mathrm{~mm}$ ) was present medial to the sagittal ridge of the third metatarsal bone at the level of the sagittal groove of the proximal phalanx. A small short radiolucent line was present in the sagittal groove of the proximal phalanx
(Figure 15). As the fracture fragment was too small for internal fixation, it was decided to remove it.

Synovial punction of the metatarsophalangeal joint revealed turbid synovial fluid. Arthroscopy of this joint was performed starting with the lateroplantar approach to flush the joint and to flush the debris in dorsal direction. Next, a dorsomedial arthroscopic approach was performed. Inspection of the joint revealed marked synovitis with an intra-articular wound dorsolaterally. Fibrin and synovial proliferations were removed using a rongeur and a shaver. The dorsolateral wound was debrided and then enlarged distally to a small arthrotomy. The intra-articular fracture fragment at the dorsolateral part of the distal third metatarsal bone was detached from the bone and the joint capsule and was removed. The joint was then extensively flushed (both dorsally and plantar), and the wound was sutured in three layers (capsule, subcutis and skin) with absorbable suture material. One gram of ceftiofur was injected to the joint. A plaster cast was placed.

Case 6

A six-year-old Belgian Warmblood showjumping horse was referred to the Surgery and Medical Imaging Department of the Faculty of Veterinary Medicine (Ghent University) for contrast CT of the left hind stifle and arthroscopy of this joint depending on the results of the CT. Three months earlier, the horse was markedly lame left hind. The horse was known to have an osseous cyst-like lesion at the lateral condyle of the femur in the left stifle and at the medial condyle of the femur in the right stifle. Ultrasonography by the referring veterinarian revealed marked medial femorotibial joint distension in left hind stifle. Conservative treatment with NSAID's and relative rest improved the lameness, but the lameness relapsed.

No orthopedic examination was requested, butradiographic examination and ultrasound of the left stifle were repeated. Radiographs confirmed the large, illdefined osseous, cyst-like lesion at the lateral condyle of the femur, with moderate surrounding sclerosis (Figure 16). Osteochondrosis of the sulcus intertrochlearis of the femur was also noted. On ultrasound, the lateral femorotibial joint was more distended, especially the subextensor recess and to a lesser degree the medial femorotibial joint. The eminentiae intercondylares were irregularly outlined and an irregular indentation was present at the cranial aspect of the eminentiae intercondylares. The cranial aspect of the lateral cranial meniscotibial ligament was within normal limits. The adjacent osseous surface was focally mildly irregularly outlined.

As requested, the horse underwent native $\mathrm{CT}$ imaging of the complete left hindlimb and contrast CT imaging of the left stifle. Thirty $\mathrm{mL}$ of $50 \%$ diluted Iomeron was injected in the lateral and medial femorotibial and femoropatellar joints under general anesthesia.

CT confirmed the osseous, cyst-like lesion in the 


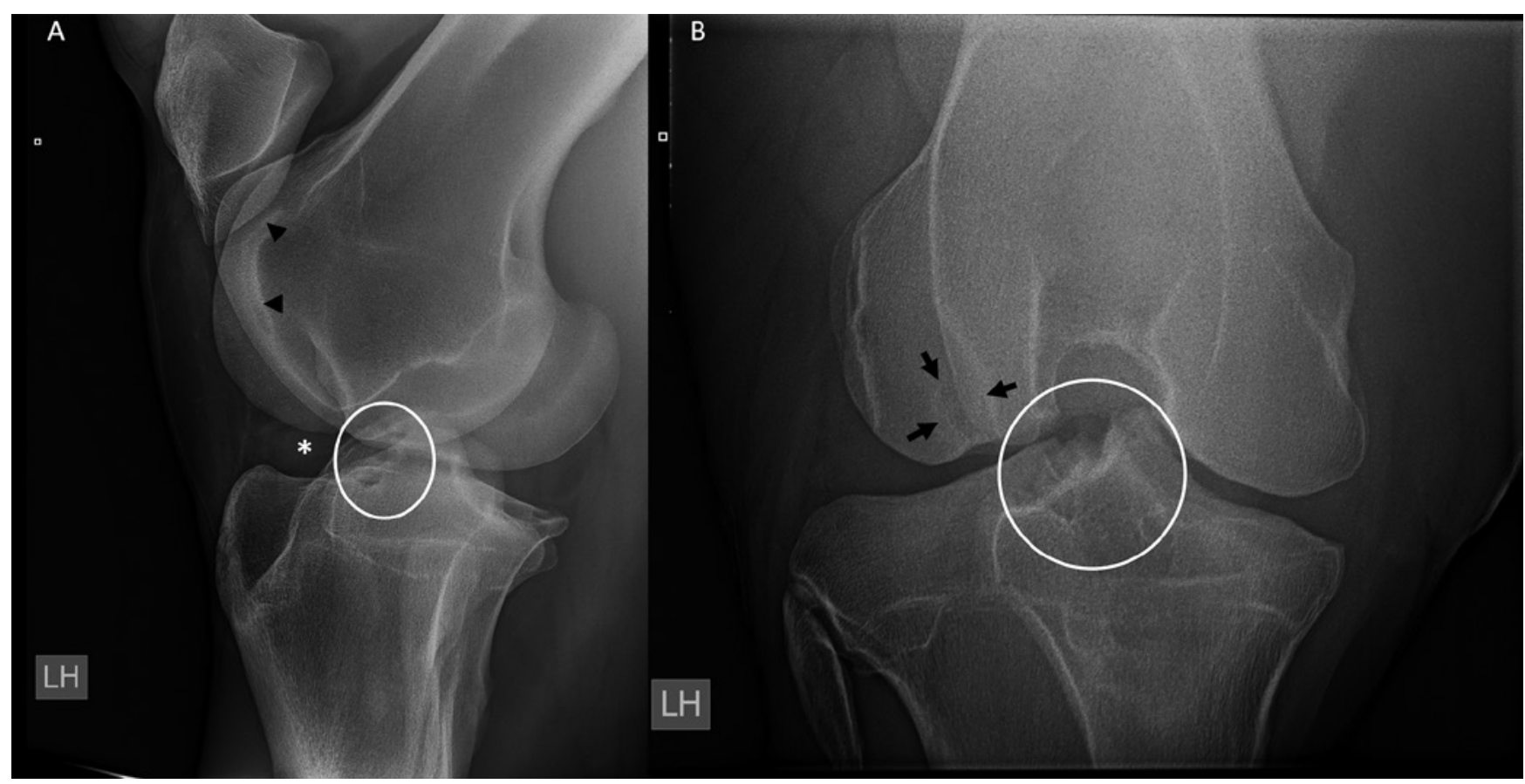

Figure 16. Case 6: A. Caudal $30^{\circ}$ lateral to craniomedial oblique and B. caudocranial radiographs of the left stifle where an ill-defined osseous cyst-like lesion is noted with surrounding sclerosis (black arrows). The cranial aspect of the eminentiae intercondylares are moderately irregularly outlined and heterogeneous (white circle). Note the increased opacity at the cranial aspect of the stifle with compression of the infrapatellar fat pad indicative of femorotibial joint distention (white asterisk). The black arrowheads indicate the osteochondrosis lesion of the sulcus intertrochlearis of the femur, which is an incidental finding.

lateral femoral condyle. The adjacent subchondral bone surface was irregularly outlined and there was an irregular interface between the articular cartilage layer and the intra-articular contrast medium. Additionally, the contrast medium was entering the cystic lesion. The findings were indicative of a large subchondral, osseous, cyst-like lesion of the lateral femoral condyle with associated cartilage defect and functional articular communication (Figure 17).
A well-defined, rounded, hypoattenuating area of bone resorption (diameter of $6.5 \mathrm{~mm}$ ) was present in the region of attachment of the cranial lateral meniscotibial ligament. Focally, the bone surface of the tibial plateau was interrupted at that level with a thin rim of surrounding sclerosis and central filling of the cyst-like lesion at the ligament insertion. There was a mild to moderate amount of bone proliferation at this level, and additionally, a marked amount of hetero-

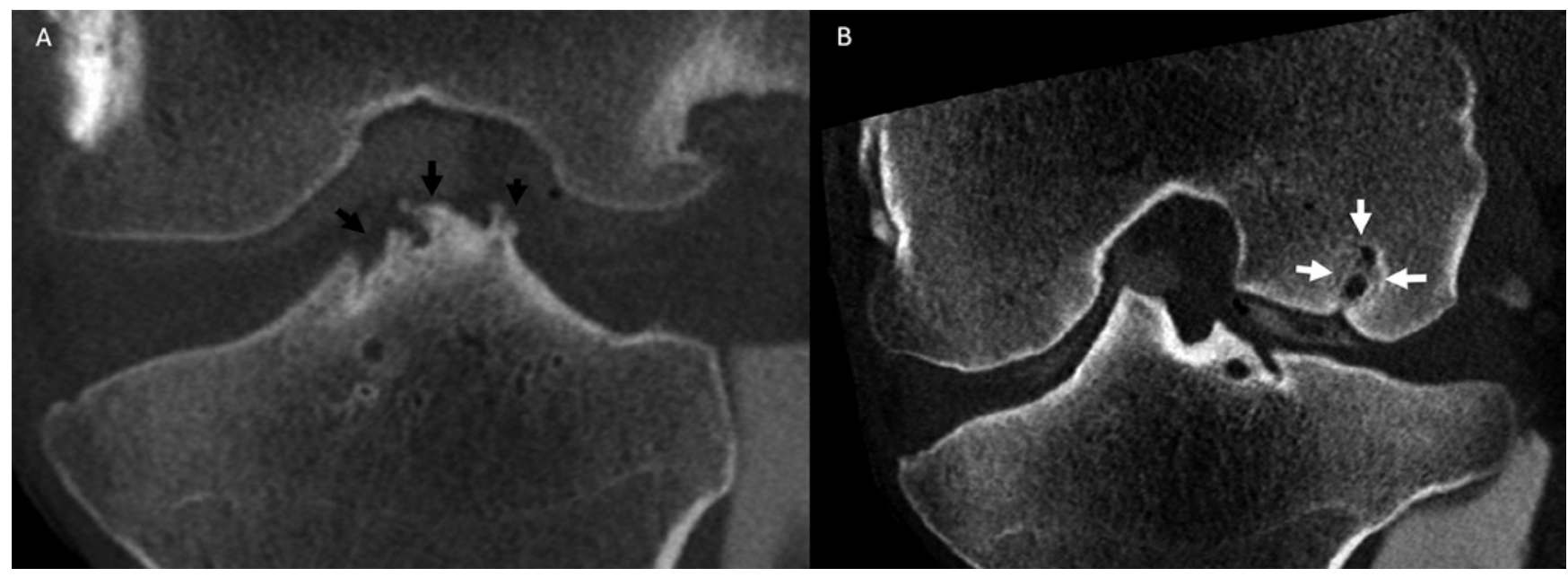

Figure 17. Case 6: Multiplanar CT reconstructions in a dorsal plane at a A. cranial and B. more caudal level. Medial is to the left. The black arrows indicate the entheseous new bone formation at the insertion of the cranial cruciate ligament and the white arrows indicate the irregularly shaped large osseous cyst-like lesion in the lateral condyle of the femur, which shows two compartments and two rims of sclerosis. 


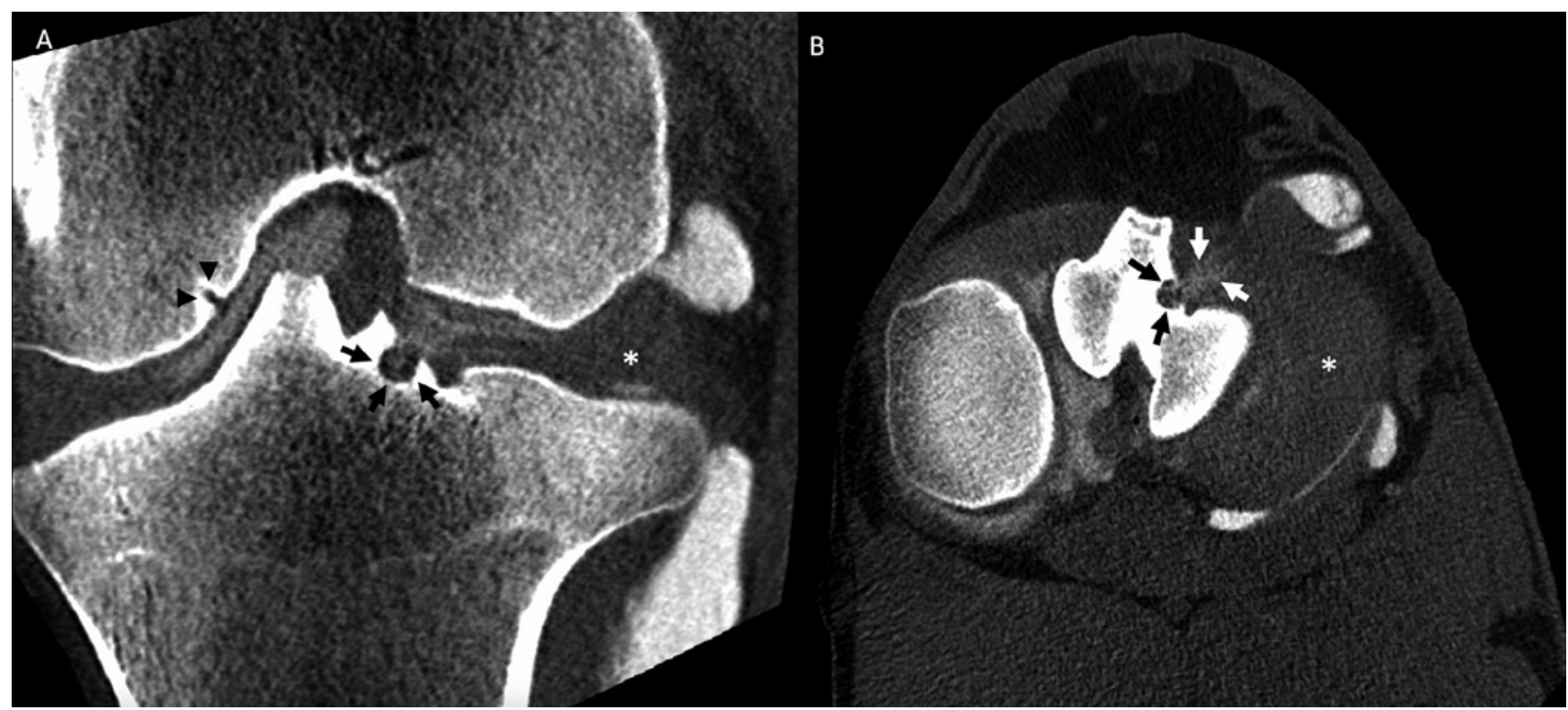

Figure 18. Case 6: Multiplanar CT reconstructions in a A. dorsal and B. transverse plane of the left stifle. Medial is to the left. The cystic enthesopathy (black arrows) and contrast leakage in the tear of the lateral cranial meniscotibial ligament (white arrows) are clearly detectable. The lateral meniscus is annotated with an asterisk. Note the small osseous cyst-like lesion at the axial aspect of the medial condyle (black arrowheads).

geneous irregularly shaped contrast medium leakage was present within the lateral cranial meniscotibial ligament extending partially further into the cranial horn of the lateral meniscus. Those findings were compatible with a marked cystic enthesopathy, desmopathy and tearing of the lateral cranial meniscotibial ligament with extension into the cranial horn of the lateral meniscus. Additionally, a small, welldefined, subchondral bone irregularity of the lateral tibial plateau was noted $(2.8 \times 2.5 \times 1.5 \mathrm{~mm})$ (Figure 18).

The lateral intercondylar eminence was markedly irregularly outlined with well-defined, irregular new bone formation, at the level of the cranial attachment of the cranial cruciate ligament, indicative of an enthesopathy of the cranial cruciate ligament (Figure 17).

A small subchondral, osseous, cyst-like lesion of the medial femoral condyle was also noted, without contrast entering the cyst, and the overlying cartilage layer was normal. Generally, there was a moderate synovitis of the lateral femorotibial joint, and to a lesser degree the medial femorotibial joint. Osteochondrosis of the sulcus intertrochlearis of the femur was present.

Arthroscopy of the stifle was proposed for additional diagnosis and simultaneous treatment of the tear of the lateral meniscus and the lateral cranial meniscotibial ligament, but the owners opted for a conservative treatment due to the severity of the lesions and the subsequent poor prognosis.

\section{DISCUSSION}

In this study, CT was necessary to diagnose the site of osteomyelitis in two young foals, to demonstrate exact configuration of fractures for surgical planning in three cases, and in one case, CT demonstrated multiple soft tissue injuries in the stifle.

Radiography is the first choice in foals presenting suspected osteomyelitis. However, there is a certain time lag between a clinically suspected lesion before it becomes radiographically apparent: it may take 21 days before radiographs become diagnostic for osteomyelitis in foals (Paradis, 2010). Therefore, if a foal is suspected of osteomyelitis and the radiographs are negative, this does not rule out an osteomyelitis lesion and follow-up radiographs after seven days or a CT scan should be performed (Paradis, 2010; Barba and Lepage, 2013; Glass and Watts, 2017). Early diagnosis and treatment are crucial to improve prognosis.

Advanced diagnostic imaging modalities have been useful in the identification of septic osteomyelitis in foals as it provides excellent visualization of bony destruction, and it is particularly useful in proximal regions where overlying soft tissues and incomplete ossification of subchondral bone limit complete evaluation of joint surfaces, subchondral bone and physis (Barba and Lepage, 2013; Glass and Watts, 2017).

In the initial presentation of case 1, only two projections of the tarsus (lateromedial and the dorsoplantar) were taken where an irregular aspect of the third tarsal bone was seen on the dorsoplantar projection and not on the lateromedial one. In a recent study in which radiography and CT in foals with osteaomyclitis were compared, the area of lysis was underestimated by $37 \%$ with lateromedical projection (Lean et al., 2018). In this case, it could have been beneficial to initially include the four projections of the tarsus to improve the visualization and the extent of the irregular aspect of the third tarsal bone. However, this is of- 
ten seen in young foals due to the ongoing ossification process, and follow-up is necessary to differentiate between the ongoing ossification and osteomyelitis (Coleman and Whitfield-Cargile, 2017). In both foals with osteomyelitis in the present case series, CT provided a good view on the severity and the extent of the lysis and was beneficial for accurate therapy. Addition of intra-venous contrast administration improves soft tissue evaluation and allows for identification of soft tissue lesions such as abscesses (Nelson et al., 2017) thereby expanding diagnostic capabilities.

The small body size of young foals allows to include large body parts and even perform full body scans. This is an advantage as it decreases the need for multiple radiographs of multiple joints. This is advantageous when the clinical examination fails to point out the exact origin of lameness. CT may actually result in cost saving by providing an earlier diagnosis and decreasing hospitalization duration (Paradis, 2010).

It is not surprising that the majority of cases in this series includes patients with fractures. CT is the modality of choice for pre-operative planning of fracture repair as it allows the production of cross-sectional images with superior bone resolution that assist in the identification of the number and direction of fracture planes, especially in complex fractures (Bergman and Saunders, 2011).

With the increasing availability of CT, this modality is being more frequently used for surgical planning and repair of fractures in horses. Computed assisted surgery is mainly used for the fracture repair of the distal limb including the tarsus, metatarsus, metacarpus, proximal, middle and distal phalanx (Perrin et al., 2010; Perrin et al., 2011).

To the authors' knowledge, pre-operative computed tomography for elbow and shoulder fractures has not been reported in the literature; yet, it has proven its benefits in planning, executing and in the results of the surgery in the present cases. Based on the CT images, the most optimal surgical technique could be chosen due to the exact visualization of the fracture planes and fragment localization. Additionally, the fragments could be accurately measured and thus the surgeon was able to decide to remove the small fragments and choose the correct size of the surgical implants on beforehand.

Only one case of stifle injury was examined in this case series. Native CT combined with CT arthrography is the modality of choice to visualize the complete stifle including the soft tissue structures (Van der Vekens et al., 2011). Radiography, ultrasonography, nuclear scintigraphy and diagnostic arthroscopy have been described in the diagnosis of stifle pathology in the horse, but these techniques also have limitations. Radiography and nuclear scintigraphy are useful for the evaluation of bone structures and soft tissue entheses, but are limited by superimposition of the musculature and the size of the bone structures and are considered less useful for the evaluation of the soft tissue structures (Maulet et al., 2005). Ultrasonography is limited to the superficial bone and soft tissue structures. Evaluation of certain structures, such as the cruciate ligaments is extremely difficult (Hoegaerts et al., 2005). Diagnostic arthroscopy can be useful for the evaluation of the articular cartilage, portions of the menisci and associated ligaments, but certain anatomical areas of the stifle cannot be reached, including the bodies of the menisci, most of the cartilage of the tibial plateau, the caudal part of the condyles of the femur and the caudal part of the cranial cruciate ligament (Walmsley, 2002). In human medicine, high field magnetic resonance imaging (MRI) is the modality of choice to diagnose stifle injury (Nacey et al., 2017). When MRI is not available, CT arthrography can be considered because it has been proven very accurate in diagnosing cruciate ligament, cartilage and meniscal lesions (Kalke et al., 2012). Furthermore, low field MRI of the equine stifle is not widely available and high field MRI is not possible for equine stifles at this moment. In case 6 of this series, the radiographic abnormalities at the level of the eminentiae intercondylares already indicated an enthesopathy at the level of the cranial lateral meniscotibial ligament or at the cranial cruciate ligament in combination with the large osseous cyst-like lesion in the lateral condyle. Arthrography CT confirmed the large cyst in the lateral condyle and showed functional articular communication, as well as a cystic enthesopathy of the cranial lateral meniscotibial ligament with a tear of this ligament which continued in the cranial horn of the lateral meniscus and marked enthesopathy of the cranial cruciate ligament. Thus, due to the poor prognosis and the young age (six-year-old) of this horse, the owners did not choose for arthroscopy.

In conclusion, $\mathrm{CT}$ is increasingly available and in the present case series, it has proven its additional value compared to radiography and ultrasonography, due to its earlier diagnosis of osteomyelitis in foals (cases 1 and 2), the improved pre-surgical planning for complex fractures (cases 3, 4 and 5) and the alternation of the prognosis in stifle lameness with multiple osseous and soft tissue lesions in case 6.

\section{REFERENCES}

Barba M., Lepage, O. M. (2013). Diagnostic utility of computed tomography imaging in foals: 10 cases (20082010). Equine Veterinary Education 25, 29-38.

Bergman E. H. J., Saunders J. H. (2011) Equine fractures. In: Schwarz T. and Saunders J. H. (editors). Veterinary Computed Tomography. Wiley-Blackwell, West Sussex, 457-463.

Coleman M. C., Whitfield-Cargile C. (2017). Orthopedic conditions of the premature and dysmature foal. Veterinary Clinics of North America - Equine Practice 33, 289297.

Glass K., Watts A. E. (2017). Septic arthritis, physitis, and osteomyelitis in foals. Veterinary Clinics of North America - Equine Practice 33, 299-314. 
Hoegaerts M., Nicaise M., van Bree H., Saunders J. H. (2005). Cross-sectional anatomy and comparative ultrasonography of the equine medial femorotibial joint and its related structures. Equine Veterinary Journal 37, 520529.

Kalke R. J., Di Primio G. A., Schweitzer M. E. (2012). MR and CT arthrography of the knee. Seminars in Musculoskeletal Radiology 16, 57-68.

Lean N. E., Perkins N. R., Ahern, B. J. (2018). Comparison of conventional radiography and computed tomography as aids in the diagnosis of osteomyelitis in 11 foals. Australian Veterinary Journal 96, 257-261.

Mageed, M. (2020). Standing computed tomography of the equine limb using a multi-slice helical scanner: Technique and feasibility study. Equine Veterinary Education, $1-7$.

Maulet B. E. B., Mayhew I. G.,Jones E., Booth T. M. (2005). Radiographic anatomy of the soft tissue attachments of the equine stifle. Equine Veterinary Journal 37, 530-535.

Nacey N. C. Geeslin M. G., Miller G. W., Pierce J. L. (2017). Magnetic resonance imaging of the knee: An overview and update of conventional and state of the art imaging. Journal of Magnetic Resonance Imaging 45, 1257-1275.

Nelson B. B., Goodrich L. R., Barrett M. F., Grinstaff M. W., Kawcak C. E. (2017). Use of contrast media in computed tomography and magnetic resonance imaging in horses: Techniques, adverse events and opportunities. Equine Veterinary Journal 49, 410-424.
Paradis, M. R. (2010). Septic arthritis in the foal: What is the best imaging modality? Equine Veterinary Journal 22, 334-335.

Perrin R. A. R., Launois M. T., Brogniez L., Desbrosse F. G., Coomer R. P., Clegg P. D., Reda A. A., Gehin S. G., Vandeweerd J. M. E. F. (2010). Computed tomography to identify preoperative guidelines for internal fixation of the distal sesamoid bone in horses: an in vitro study. Veterinary Surgery 39, 1030-1036.

Perrin R. A. R., Launois M. T., Brogniez L., Clegg P. D., Coomer R. P. C. Desbrosse F. G., Vandeweerd J. M. E. F. (2011). The use of computed tomography to assist orthopaedic surgery in 86 horses (2002-2010). Equine Veterinary Education 23, 306-313.

Van der Vekens E., Bergman E. H. J., Vanderperren K., Raes E. V., Puchalski S. M., van Bree H. J. J., Saunders J. H. (2011). Computed tomographic anatomy of the equine stifle joint, American Journal of Veterinary Radiology $72,512-521$

Walmsley J. P. (2002). Arthroscopic surgery of the femorotibial joint. Clinical Techniques in Equine Practice 1, 226-233.

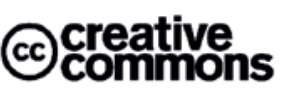

C) 2021 by the authors. Licensee Vlaams Diergeneeskundig Tijdschrift, Ghent University, Belgium. This article is an open access article distributed under the terms and conditions of the Creative Commons Attribution (CC BY) license (http://creativecommons.org/licenses/by/4.0/).

\section{Verlossing in de kerststal op het marktplein}

Collega Frans (Sus) Van Tendeloo (promotie 1976) schreef onder het pseudoniem Maarten Jagermeester een heel oeuvre bij elkaar: een indrukwekkende reeks jeugdboeken, verhalenbundels voor volwassenen en naslagwerken over dieren. De verhalen zijn niet allemaal even geloofwaardig tot in de details, maar dat mag de leespret zeker niet bederven. Zo opent zijn bundel Meneer de dierendokter, aangekondigd als De grappigste verhalen uit mijn praktijk (Houtekiet, 2019), met een bepaald indrukwekkend 'Kerstverhaal'. We lezen er in hoe de dierendokter op kerstavond een van de twee schapen - mooie Ardense Voskoppen - in de kerststal op het marktplein van een Kempisch dorp verloste van een tweeling. En dat bij min zes vrieskou, vanzelfsprekend omringd door een menigte supporters, velen rechtstreeks uit het café. En dat was nog niet alles. Het moederschaap bleek geen melk te geven. De gebruikelijke 'prik' hielp niet en een ander bracht mee dat de lammetjes uiteindelijk moesten gezoogd worden door een zeer gewillige hondenteef. Het rustige dorpje Noorderwijk had nu eindelijk een attractie waar iedereen over sprak. 